\title{
Educação ambiental e mudanças climáticas: análise do Programa Escolas Sustentáveis
}

\section{Environmental education and climate change: analyzing the Sustainable Schools Program}

\author{
ID Neyla Cristiane Rodrigues de Oliveira ${ }^{1}$ \\ Francisca Carla Silva de Oliveira ${ }^{2}$ \\ Denis Barros de Carvalho 3

\begin{abstract}
'Instituto Federal de Educação, Ciência e Tecnologia do Piauí (IFPI), Campus São João do Piauí, Pl, Brasil. Autora Correspondente: profa.neylaoliveira@gmail.com

${ }^{2}$ Universidade Federal do Piauí (UFPI), Centro de Ciências da Educação, Departamento de Métodos e Técnicas de Ensino, Teresina, PI, Brasil.

${ }^{3}$ Universidade Federal do Piauí (UFPI), Programa de Pós-Graduação em Desenvolvimento e Meio Ambiente,
\end{abstract} \\ Teresina, PI, Brasil.
}

Resumo: A Educação Ambiental (EA) tem potencial de contribuir para transformações socioambientais fundamentais na sociedade contemporânea. Nesse sentido, objetivou-se analisar as propostas pedagógicas desenvolvidas pelo Programa Escolas Sustentáveis, na perspectiva da EA e das Mudanças Climáticas (MC) em Teresina, Piauí. O estudo possui natureza qualitativa e foi realizado como pesquisa documental, com o uso das seguintes palavras-chave: EA, MC, sustentabilidade, perda da biodiversidade, refugiados ambientais, movimentos sociais e meio ambiente. Para interpretação dos dados, utilizou-se análise de conteúdo. Após leitura flutuante, chegou-se às seguintes categorias: Educação e sustentabilidade na escola; EA e sensibilização ambiental; Educação, MC e ações antropogênicas. Constatou-se que a discussão sobre as MC é incipiente no contexto escolar, mesmo que haja, no currículo, conhecimentos referentes à dinâmica climática, fenômenos climáticos, zonas climáticas e domínios morfoclimáticos; sendo essencial promover reflexões sobre EA e MC. Para tanto, é importante implementar políticas públicas e desenvolver propostas pedagógicas voltadas para a educação climática integrada à EA.

Palavras-chave: Educação ambiental; Políticas públicas; Mudança climática; Projeto Pedagógico.

Abstract: Environmental Education (EE) has the potential to contribute to fundamental socio-environmental transformations in contemporary society. In this sense, the objective in this study was to analyze the pedagogical proposals developed by the Sustainable Schools Program, from the perspective of EE and Climate Change (CC) in Teresina, Piauí state, Brazil. The qualitative study consisted of documentary research. We used content analysis to interpret the data. After floating reading, the following categories were established: Education and sustainability at school; EE and environmental awareness; Education, CC, and anthropogenic actions. It was found that the discussion about CC is incipient in the school context, even if topics are part of the curriculum, such as: knowledge regarding climate dynamics, climatic phenomena, climate zones and morphoclimatic domains; it is essential to promote reflections on EA and CC. Therefore, it is important to implement public policies and develop pedagogical proposals aimed at climate education integrated with EE.

Keywords: Environmental education; Public policy; Climate change; Pedagogical project.

Recebido em: 13/10/2020

Aprovado em: 01/09/2021 


\section{Introdução}

As Mudanças Climáticas (MC) têm gerado diversos efeitos sobre as populações, especialmente aquelas mais vulneráveis socioeconomicamente, e para os ecossistemas, exigindo medidas voltadas à adaptação climática, por parte dos planejadores urbanos e dos formuladores de políticas públicas (TEIXEIRA; PESSOA, 2020; TEXEIRA; PESSOA; DI GIULIO, 2020). Dessa maneira, a pesquisa em educação sobre MC deve incluir estratégias de mitigação com valores de Educação Ambiental (EA), uma vez que contribui para a qualidade de vida e do meio a mbiente, com transformações socioeconômicas e culturais, que visam a sustentabilidade (KRASNY; DUBOIS, 2016; MESQUITA et al., 2019).

O tema Mudanças Climáticas tem sido amplamente discutido pela pesquisadora Michèle Sato, que o nomeia como "crise climática", e se revela como complexa e multidisciplinar, que envolve aspectos econômicos, interesses específicos, posicionamentos políticos e igualdades de direitos. Estes devem ser considerados em processos formativos de educadores ambientais, bem como a justiça climática, que preconiza o acesso aos processos educativos por grupos em situação de vulnerabilidade, de forma a possibilitar as melhores escolhas e a elaboração de medidas que minimizem as ameaças do clima (SATO, 2003, 2014, 2020; SOUZA; SATO, 2019).

Nessa perspectiva, deve-se implementar políticas públicas e tomadas de decisão, dos gestores e da sociedade em geral, a respeito do desenvolvimento de atividades que reduzam a emissão de Gases de Efeito Estufa (GEE), mas, sobretudo, que facilitem a formação do cidadão e a promoção da educação climática (BUSCH; HENDERSON; STEVENSON, 2019; SILVA; FRANÇA, 2018).

A educação climática consiste no estudo de conceitos e termos técnicos sobre as MC, considerando as medidas de adaptação e mitigação das suas causas e efeitos, de acordo com Blumenthal e Kropp (2019), Hess e Maki (2019), Kuster e Fox (2017) e Ojala (2019). Diante disso, a Comissão de Meio Ambiente e Qualidade de Vida na Escola (COM-VIDA) auxilia na criação e na ampliação de projetos de EA, com o intuito de tornar a escola um ambiente sustentável que, por meio do fazer pedagógico, colabore com a construção de conhecimentos e valores, formando cidadãos críticos, reflexivos e conscientes, frente a problemática climática.

A COM-VIDA foi uma das propostas da Política Pública Vamos Cuidar do Brasil, resultado da I Conferência Nacional Infantojuvenil pelo Meio Ambiente (I CNIJMA), realizada em 2003. Participam da COM-VIDA: estudantes, professores, funcionários, gestores e comunidade; contribuindo para o dia a dia participativo, democrático, dinâmico e saudável, impulsionando o intercâmbio entre escola e comunidade, com o objetivo de incentivar jovens educadores ambientais, dispostos a trabalhar as problemáticas socioambientais e implementar a Agenda 21 em espaços educativos formais (BELASCO et al., 2020; BRASIL, 2007).

As Conferências Infantojuvenis pelo Meio Ambiente já existem há 16 anos e, em 2018, ocorreu a sua 5 a edição, intitulada: Vamos Cuidar do Brasil Cuidando das Águas. As edições anteriores detinham um enfoque que objetivava a inserção de crianças e jovens no exercício de elaboração das políticas públicas direcionadas ao meio ambiente. É de responsabilidade das Secretarias de Educação promover o evento local, no qual são 
escolhidos os delegados que participam da Conferência Nacional, realizada em Brasília, com estudantes e educadores de todo o Brasil, a fim de discutirem a problemática ambiental.

A COM-VIDA pode indicar o caminho em direção ao desenvolvimento da cultura de respeito ao meio ambiente e à sociedade mais sustentável. Com relação à educação, uma alternativa para tornar as escolas sustentáveis seria investir em programas com responsabilidade e foco na realidade local, almejando a execução de projeto em curto, médio e longo prazo, baseado no currículo escolar (BELASCO et al., 2020; SILVA; BASTOS; RIBEIRO, 2019). Além disso, a continuidade das ações de EA com alunos e professores engajados, participantes ativos de novas práticas, que ressignifiquem o ensino, superem o consumismo e amenizem a crise civilizatória (SANTOS et al., 2017).

Segundo Silva et al. (2019), os educadores devem estar atentos para questões, como: degradação ambiental, riscos e desastres naturais, pobreza e desigualdade social e, especialmente, ameaças à paz e à segurança. Assim, apoiado nos eixos Gestão, Currículo e Estrutura, o Programa Nacional Escolas Sustentáveis (PNES) buscou oportunizar, mediante a criação de espaços educativos sustentáveis, o surgimento de agentes de mudança em prol da sustentabilidade.

A Secretaria Municipal de Educação de Teresina (SEMEC), por intermédio do Núcleo de Educação Ambiental (NEA), implementou, em 2014, o Programa Escolas Sustentáveis (PES) na Rede Municipal de Ensino de Teresina (RMET), com recursos do Fundo Nacional de Desenvolvimento da Educação (FNDE), a fim de atingir os objetivos da Agenda 21, criação das COM-VIDA e realização de atividades de EA, que envolvessem a comunidade local.

Nesse sentido, é relevante, no campo científico atual, a realização de estudos que abordem as MC no cenário das Escolas Sustentáveis, visto que elas têm abrangência local e global, e pesquisas desta natureza são incipientes, principalmente no estado do Piauí. Desse modo, pretende-se responder o seguinte questionamento: Qual a situação da RMET com relação ao Programa Escolas Sustentáveis (PES), no contexto da EA e das MC? Assim sendo, objetivou-se analisar as propostas pedagógicas desenvolvidas pelo PES, na perspectiva da EA e das MC, Teresina, Piauí.

\section{Material e Métodos}

O estudo possui natureza qualitativa, com a realização de pesquisa documental (quadro 1) que, para Gil (2008), consiste na análise de documentos que ainda não receberam tratamento analítico ou que podem ser reelaborados de acordo com os objetivos da pesquisa, bem como ganhar novas interpretações.

Quadro 1 - Relação dos documentos para análise da situação da RMET, Teresina, Piauí

\begin{tabular}{|c|c|c|c|}
\hline Identificação & Título & Organização & Ano \\
\hline Documento 1 & $\begin{array}{l}\text { Formando COM-VIDA - Comissão de Meio } \\
\text { Ambiente e Qualidade de Vida na Escola: } \\
\text { construindo Agenda } 21 \text { na escola }\end{array}$ & $\begin{array}{l}\text { Ministério da Educação (MEC) e Ministério do } \\
\text { Meio Ambiente (MMA) }\end{array}$ & 2007 \\
\hline Documento 2 & Diretrizes Curriculares de Teresina (DCT) & $\begin{array}{l}\text { Secretaria Municipal de Educação de Teresina } \\
\text { (SEMEC) }\end{array}$ & 2008 e 2018 \\
\hline Documento 3 & Relatório Programa Escolas Sustentáveis (PES) & Núcleo de Educação Ambiental (NEA) da SEMEC & 2014 a 2017 \\
\hline
\end{tabular}

Fonte: elaborado pelos autores. 
Realizou-se análise de frequência nos documentos selecionados (quadro 1) das palavras-chave: EA, MC, sustentabilidade, perda da biodiversidade, refugiados ambientais, movimentos sociais e meio ambiente. A escolha dessas palavras ocorreu pelo fato de serem termos relacionados às causas e aos efeitos das MC e ao objetivo da pesquisa.

O processo de análise de dados envolveu várias etapas para auferir significação às informações coletadas. Diante dessa diversificação e da aproximação terminológica, optou-se por elencar os passos da técnica, segundo Bardin (2011), que organiza os em três fases: (1) pré-análise; (2) exploração do material; e (3) tratamento dos resultados, inferência e interpretação.

Para realização da leitura flutuante, focou-se nos objetivos, com a finalidade de elaborar o que Bardin (2011) define por índices. Primeiramente, foram destacadas as palavras-chave e a contagem das ocorrências nos documentos. Em seguida, realizou-se o recorte de trechos que chamavam a atenção sobre a temática das MC. Por fim, as palavraschave e os trechos foram utilizados como indicadores para formulação das categorias de estudo.

\section{Resultados e discussão}

Após a construção de indicadores que auxiliaram no processo de categorização, destacaram-se pontos que remetiam à relação entre educação, sustentabilidade, sensibilização ambiental, MC e ações antropogênicas. Dessa forma, os resultados desta pesquisa foram organizados em três categorias de estudo:

1. Educação e sustentabilidade na escola;

2. Educação ambiental e sensibilização ambiental;

3. Educação, mudanças climáticas e ações antropogênicas.

\section{Educação e sustentabilidade na escola}

Para Freire (2007), educar é construir, criar no sujeito a consciência da liberdade e a possibilidade de romper com o determinismo, trazendo na educação o reconhecimento do indivíduo que arquiteta e interfere na história e na realidade de hoje e do futuro. Entende-se que, neste contexto, é necessário propor práticas pedagógicas que permeiam o ato de educar, a valorização e a vivência da identidade cultural. É a partir das experiências dos educandos, de sua identidade e história, a possibilidade de inserir o indivíduo no processo educacional. De acordo com Freire (1991, p. 80), "[...] a formação do educador deve instrumentalizá-lo para que ele crie e recrie a sua prática através da reflexão sobre o seu cotidiano".

O caminho para uma sociedade sustentável se fortalece à medida que se ampliam propostas pedagógicas, pautadas pelo paradigma da complexidade e, por sua vez, conduzam atitudes reflexivas em torno da problemática ambiental, almejando conceituar o ambiente para formação de cidadãos, conhecimentos e comportamentos (JACOBI, 2014). Nesse sentido, as palavras-chave que mais a pareceram nos documentos foram: meio ambiente (76 vezes), EA (62 vezes) e sustentabilidade (27 vezes) (quadro 2). Isso porque são trabalhados temas socioambientais, meio ambiente, caminhos para uma sociedade sustentável, princípios da EA, ações e projetos para discutir as questões ambientais na escola. 
Quadro 2 - Ocorrências das palavras-chave nos documentos Formando COM-VIDA, Diretrizes Curriculares de Teresina e Relatórios COM-VIDA

\begin{tabular}{|l|r|}
\hline \multicolumn{1}{|c|}{ Palavras-chave } & Ocorrências \\
\hline Meio ambiente & 76 \\
\hline Educação ambiental & 62 \\
\hline Sustentabilidade & 27 \\
\hline Movimentos sociais & 3 \\
\hline Mudanças climáticas & 2 \\
\hline Perda da biodiversidade & 2 \\
\hline Refugiados ambientais & 1 \\
\hline
\end{tabular}

Fonte: elaborado pelos autores.

No contexto de investigação da educação climática, o termo Mudanças Climáticas foi citado duas vezes no documento 1. Na primeira, apareceu como uma das temáticas debatidas na II CNIJMA, que, por meio das COM-VIDA, ocorreram ações e atividades nas escolas, com o envolvimento dos alunos, dos professores e da comunidade local. $\mathrm{Na}$ segunda, as MC são apresentadas como tema global, complexo e urgente, que precisa ser considerado pela sociedade contemporânea, em especial os pesquisadores em educação, com a finalidade de sensibilizar e mobilizar as pessoas, para juntos encontrar alternativas para os desafios socioambientais decorrentes das MC.

No documento 2, a palavra-chave Mudanças Climáticas não apresentou ocorrência, mas termos correspondentes, como dinâmica climática, fenômeno climático, domínio morfoclimático, zonas climáticas, variedades climáticas; demostrando que conceitos relacionados estão presentes no currículo. Isso pode dar espaço para os educadores refletirem sobre a educação climática, de forma que sejam abordados, além desses conceitos técnicos, discussões sobre as causas e consequências das MC, sua relação com ações antropogênicas e práticas de EA, que auxiliem na busca de estratégias de adaptação e mitigação.

Diante disso, Nóbrega e Cleophas (2016) afirmam que é preciso inserir, em todas as áreas do conhecimento, tópicos, tais como Perda da Biodiversidade, Preservação dos Recursos Naturais, MC, Segurança Alimentar, Segurança Hídrica, dentre outros, que contemplem os problemas locais e a relação com o contexto global, fortalecendo a construção da cidadania planetária e igualmente inclusiva, condizente com as questões socioambientais contemporâneas.

No documento 3, não foi observada a ocorrência da palavra-chave Mudanças Climáticas e nem termos correspondentes, mas a EA foi apontada como uma das formas de se abordar as questões socioambientais em escolas sustentáveis. Dessa forma, como o professor poderia trabalhar a temática MC no contexto escolar? Primeiramente, devese conhecer a realidade local, pois, de acordo com Valois e Cavalari (2015), as políticas públicas podem gerar mudança no significado da proposta educacional inicial, quando pensada e escrita para as melhores escolas possíveis, com pouco reconhecimento de variações de contexto, recursos ou capacidades locais, sem pôr em ação a realidade vivenciada pelas instituições de ensino.

Partindo desse princípio, Teresina é um município onde as altitudes máximas raramente ultrapassam $130 \mathrm{~m}$ acima do nível do mar, com superfícies pouco onduladas. Localizada em uma região de baixa latitude, no interior do continente e com cotas altimétricas pouco elevadas, apresenta naturalmente predisposição ao 
desenvolvimento das altas temperaturas e possui um período do ano conhecido por $B-R-O-B R O ́$, no qual as temperaturas são mais elevadas nos meses de setembro, outubro, novembro e dezembro, sendo necessário pensar em práticas construtivas que considerem tais características (ABREU; ANDRADE, 2019; ANDRADE, 2016).

Segundo Andrade (2009 apud ABREU; ANDRADE, 2019), as temperaturas mínimas alcançam os $25^{\circ} \mathrm{C}$, as médias ultrapassam os $30^{\circ} \mathrm{C}$, valores bem acima dos registros anuais, e as máximas atingem $40^{\circ} \mathrm{C}$. Além disso, Teresina pode ser considerada Mesopotâmia brasileira, por estar localizada entre dois rios, Parnaíba e Poti, e possuir parques ambientais, que dispõem de natureza exuberante e diversas espécies da fauna e da flora. Desse modo, os educadores têm espaços propícios para articular temáticas ambientais, como meio ambiente, EA, sustentabilidade e MC; pois os alunos, além de estudar a teoria, podem observar, na prática, e perceber, no cotidiano, os conhecimentos apreendidos. Para tanto, podem ser realizadas aulas de campo às margens dos rios, nos parques ambientais, bem como em espaços no entorno da escola, para contemplação da natureza e percepção da temperatura.

Nesta categoria, percebeu-se que as discussões sobre MC ainda são sucintas, tanto nos documentos oficiais relacionados às Escolas Sustentáveis quanto no Currículo do Ensino Fundamental do município de Teresina. Dessa forma, faz-se necessário articular a gestão, a equipe pedagógica e as DCT, a fim de desenvolver práticas de ensino e ações de EA para abordar as MC na escola, formando cidadãos críticos, reflexivos e sensibilizados com as questões ambientais e climáticas.

\section{Educação ambiental e sensibilização ambiental}

Desde 2012 já eram desenvolvidas atividades de EA nas escolas municipais de Teresina, pensando na sensibilização ambiental e na formação de cidadãos mais conscientes. Porém, apenas em 2014 foi implementado o PES, que funcionou a partir das etapas demonstradas na figura 1.

Figura 1 - Etapas para implementação do Programa Escolas Sustentáveis na RMET, Teresina, Piauí

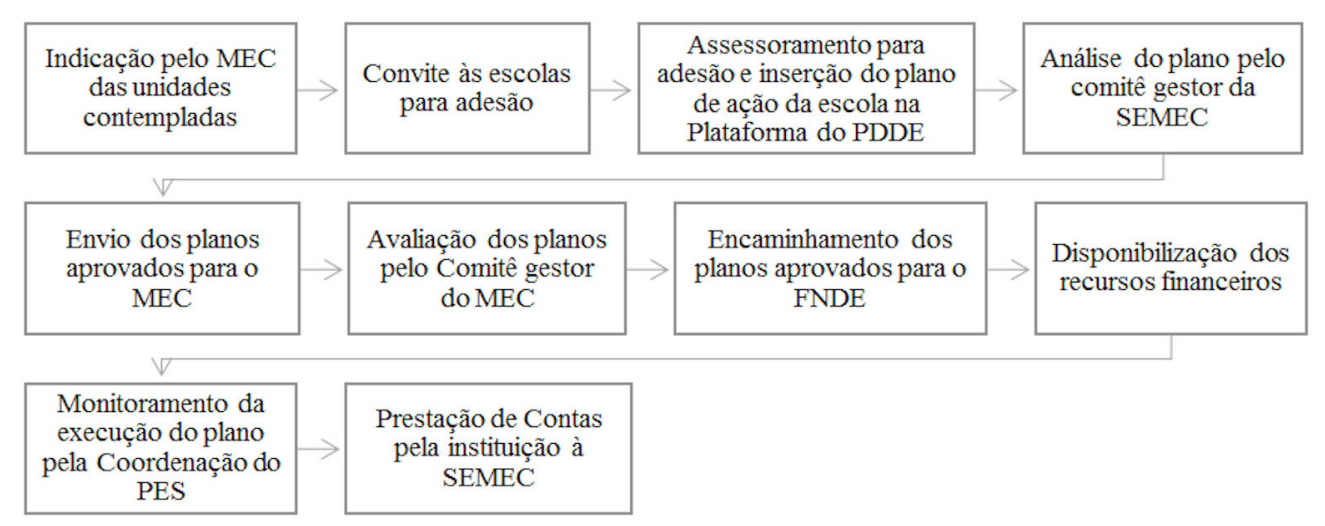

Fonte: elaborada pelos autores.

A Coordenação do PES apoiou as escolas na execução dos planos de ação, promoveu o assessoramento individual, por meio de agendamentos com os diretores das unidades de ensino, aos quais foram apresentadas as diretrizes e disponibilizados materiais referentes à temática, bem como a Rede de parceiros que desenvolvem atividades paralelas de EA. Assim, o NEA da SEMEC efetuou o monitoramento do PES, 
atendendo instituições que receberam recursos do FNDE para implantação de ações de educação e estruturação de espaços verdes, aquisição de equipamentos e orientação de atividades educativas voltadas para temáticas ambientais com alunos e comunidade, de acordo com a Resolução n 18 de $2014{ }^{1}$.

Nesse contexto, o NEA/SEMEC dispôs a missão de implementar o PES em 175 unidades de ensino, com recursos do MEC/FNDE, por meio de projetos pedagógicos ambientais, para a ambientação de espaços da escola, desenvolvimento de áreas de convivência, leitura e inserção da temática ambiental no Projeto Político Pedagógico (PPP). Para tanto, foram realizadas melhorias nos espaços físicos das instituições da RMET, inclusão da temática socioambiental no PPP e criação da COM-VIDA. No ano de 2018, o Programa atendeu 45 escolas que concluíram os planos de ação. Ao todo foram 176 unidades contempladas pelo PES entre o ano de 2014 e 2017.

Para Favero (2017), a escola é lugar de vivências, com interações e construções, sendo desafio para os professores potencializar essa ambientação por parte do educando, para que haja aprimoramento na relação sujeito-ambiente. Ambientação é o "ato ou efeito de ambientar-se", conforme Bueno (2007, p. 55), diz respeito a um processo com ritmo próprio, gradativo e singular, ou seja, cada indivíduo possui particularidades que são consideradas no reconhecimento e na adaptação ao novo espaço, metodologias e comunidade escolar.

Desse modo, o PES promoveu transformações nas instituições de ensino, com mudanças na estrutura física, mas principalmente no desenvolvimento de propostas pedagógicas para abordar os temas ambientais de importância local. Para Elali (2003), a escola mostrou-se exemplo na diferença entre o discurso e a prática social, sendo essencial trabalhar em direção ao ideal da sustentabilidade socioambiental e à qualidade de vida no espaço escolar.

Partindo dessa premissa, nos relatórios da COM-VIDA, que versam sobre as propostas pedagógicas promovidas pelo PES, observou-se que nos projetos de EA foram abordados temas, como: violência, sensibilização ambiental, meio ambiente, tráfico de animais silvestres, educação no trânsito, resíduos sólidos, reciclagem e coleta seletiva (figura 2 ).

Figura 2 - Os principais temas abordados nas propostas pedagógicas do PES da RMET, Teresina, PI

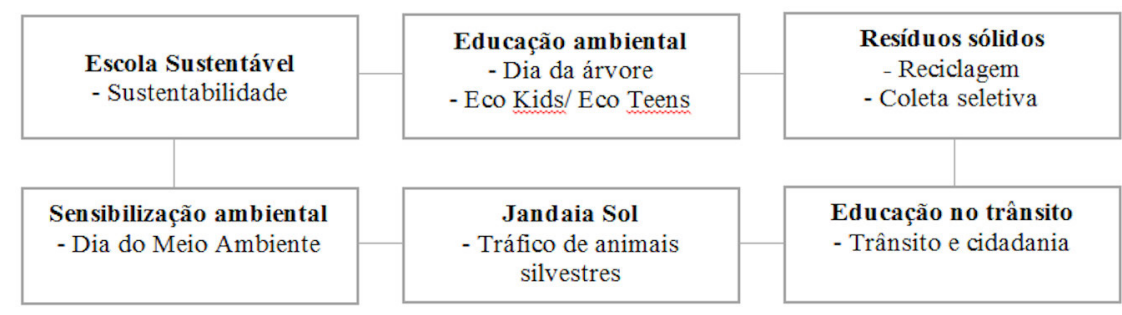

Fonte: elaborada pelos autores.

Diante desses dados, observou-se que o tópico MC não esteve presente nas discussões dos projetos do PES, o que pode promover o distanciamento da comunidade escolar com o fenômeno climático, sendo importante inserir esse tema no âmbito educacional para desenvolver medidas de mitigação e adaptação à problemática.

'Dispõe sobre a destinação de recursos financeiros, nos moldes operacionais e regulamentares do Programa Dinheiro Direto na Escola (PDDE), a fim de favorecer a melhoria da qualidade de ensino e a promoção da sustentabilidade socioambiental nas unidades escolares. 
Foram desenvolvidos projetos de EA que envolveram alunos, gestores, professores e comunidade local: Eco Kids/Eco Teens, Queremos Paz, Jandaia Sol, Projeto Educação Ambiental e Educação Ambiental em Defesa da Vida. Para isso, realizaram-se seminários de EA para formação docente e equipe gestora, a fim de capacitá-los no planejamento e execução das atividades na escola. Parcerias com o Ministério Público do Piauí (MPPI), Secretaria Municipal de Meio Ambiente (SEMMA), Associação do Comércio Agropecuário do Estado do Piauí (ACAPI), Instituto Nacional de Processamento de Embalagens Vazias (INPEV) e Instituto Brasileiro de Meio Ambiente (IBAMA) (quadro 3).

Quadro 3 - Relação dos projetos de EA desenvolvidos pelo NEA/SEMEC, parcerias, objetivo/ missão, desenvolvimento e reflexões

\begin{tabular}{|c|c|c|c|c|}
\hline Projetos & Início/Parcerias & Objetivo/missão & Desenvolvimento & Reflexões \\
\hline $\begin{array}{l}\text { Eco Kids/Eco } \\
\text { Teens }\end{array}$ & $\begin{array}{l}\text { Realizado no ano de } \\
2016 \text {, em parceria } \\
\text { com o MPPI, por meio } \\
\text { do Centro de Apoio } \\
\text { Operacional em Defe- } \\
\text { sa do Meio Ambiente } \\
\text { (CAOMA) e Centro de } \\
\text { Apoio Operacional de } \\
\text { Defesa da Educação } \\
\text { e da Cidadania (CAO- } \\
\text { DEC). }\end{array}$ & $\begin{array}{l}\text { Promover a sensibili- } \\
\text { zação e a EA nas esco- } \\
\text { las da RMET. }\end{array}$ & $\begin{array}{l}\text { Contou com a adesão das escolas para } \\
\text { a articulação de ações pedagógicas } \\
\text { voltadas para a EA, com fins de produção } \\
\text { do Jornal Eco Kids/ Eco Teens. }\end{array}$ & $\begin{array}{l}\text { Apresentou boa aceitação } \\
\text { das escolas e da comunidade } \\
\text { local, das quais participaram } \\
\text { nove escolas, } 3.500 \text { alunos } \\
\text { e } 240 \text { profissionais, além } \\
\text { disso, foram produzidos } \\
10.300 \text { jornais. É preciso } \\
\text { continuar projetos desta } \\
\text { natureza, que produzam } \\
\text { materiais ilustrativos sobre } \\
\text { meio ambiente, EA eações de } \\
\text { sustentabilidade ambiental. }\end{array}$ \\
\hline $\begin{array}{l}\text { Queremos } \\
\text { Paz }\end{array}$ & $\begin{array}{l}\text { Criado em 2016, em } \\
\text { parceria com o Centro } \\
\text { de Apoio em Defesa } \\
\text { da Educação e Cida- } \\
\text { dania do MPPI. }\end{array}$ & $\begin{array}{l}\text { Sensibilizar alunos, } \\
\text { professores e famílias } \\
\text { sobre a cultura de paz, } \\
\text { a fim de minimizar a } \\
\text { sensação de insegu- } \\
\text { rança e violência na } \\
\text { comunidade. }\end{array}$ & $\begin{array}{l}\text { Distribuíram materiais pedagógicos } \\
\text { para alunos, professores e pais, } \\
\text { apresentaram palestras, atividades } \\
\text { de sensibilização com os discentes e } \\
\text { movimentos culturais com vistas ao } \\
\text { desenvolvimento de uma cultura de } \\
\text { paz, além do compartilhamento das } \\
\text { experiências com as famílias. }\end{array}$ & $\begin{array}{l}\text { Neste projeto, poderiam ser } \\
\text { ampliadas as ações de EA e } \\
\text { inseridas discussões sobre } \\
\text { 'violência climática', no qual, } \\
\text { grupos sociais perdem suas } \\
\text { identidades ao se deslocarem } \\
\text { do local de origem em } \\
\text { decorrência das MC. }\end{array}$ \\
\hline Jandaia Sol & $\begin{array}{l}\text { Em parceria com } \\
\text { SEMMA e IBAMA, foi } \\
\text { implantado no ano } \\
\text { de } 2017 .\end{array}$ & $\begin{array}{l}\text { Promover a EA sobre } \\
\text { a problemática do } \\
\text { tráfico de animais sil- } \\
\text { vestres, além da for- } \\
\text { mação dos professo- } \\
\text { res e disponibilização } \\
\text { de materiais sobre a } \\
\text { temática. }\end{array}$ & $\begin{array}{l}\text { Em } 10 \text { escolas da RMET, com } \\
\text { apresentações lúdicas, palestras } \\
\text { sobre o tráfico de animais silvestres } \\
\text { e reconhecimento da ave símbolo do } \\
\text { município, a Jandaia Sol. } \\
\text { No ano de } 2018 \text {, foram distribuídas } \\
5.000 \text { revistas Jandaia Sol para as escolas } \\
\text { participantes, com os trabalhos dos alu- } \\
\text { nos em redação e poemas. Além disso, } \\
\text { foi feita formação para os pedagogos e } \\
\text { disponibilizado material de leitura em } \\
\text { histórias em quadrinhos para os alunos. }\end{array}$ & $\begin{array}{l}\text { Neste projeto, poderiam } \\
\text { ampliar as ações de EA e } \\
\text { inseridas discussões sobre a } \\
\text { perda da biodiversidade em } \\
\text { decorrência das MC. }\end{array}$ \\
\hline $\begin{array}{l}\text { E d u c a ção } \\
\text { Ambiental }\end{array}$ & $\begin{array}{l}\text { Projeto de Educação } \\
\text { Ambiental da ACAPI, } \\
\text { em parceria com o } \\
\text { INPEV. }\end{array}$ & $\begin{array}{l}\text { Promover a EA sobre } \\
\text { a problemática dos } \\
\text { resíduos sólidos para } \\
\text { o meio ambiente. }\end{array}$ & $\begin{array}{l}\text { Foi realizado em } 12 \text { escolas com } \\
\text { a temática Resíduos Sólidos: uma } \\
\text { responsabilidade compartilhada, } \\
\text { desenvolvendo ações educativas para } \\
\text { a promoção da EA, no que se refere } \\
\text { aos resíduos sólidos. Além disso, foram } \\
\text { executadas } 10 \text { oficinas sobre reciclagem } \\
\text { e a coleta seletiva. }\end{array}$ & $\begin{array}{l}\text { Neste projeto, poderiam } \\
\text { inserir novas discussões } \\
\text { como consumo sustentáve } \\
\text { e MC. }\end{array}$ \\
\hline $\begin{array}{l}\text { Ed u c a ção } \\
\text { Ambiental } \\
\text { em Defesa } \\
\text { da Vida }\end{array}$ & $\begin{array}{l}\text { Substituiu o Projeto } \\
\text { Eco Kids/ Eco Teens } \\
\text { em } 2018 .\end{array}$ & $\begin{array}{l}\text { Promover ações de } \\
\text { EA para a sustentabi- } \\
\text { lidade ambiental em } \\
\text { escolas da RMET. }\end{array}$ & $\begin{array}{l}\text { Foi implementado em } 13 \text { Centros de } \\
\text { Educação Infantil que desenvolveram } \\
\text { ações de sustentabilidade ambiental. }\end{array}$ & $\begin{array}{l}\text { Neste projeto, poderia pro } \\
\text { mover ações de EA e climáti- } \\
\text { ca, uma vez que trabalha com } \\
\text { a sustentabilidade ambiental } \\
\text { por exemplo: projetos de ar- } \\
\text { borização. }\end{array}$ \\
\hline
\end{tabular}

Fonte: elaborado pelos autores. 
O projeto Eco Kids/Eco Teens apresentou potencial para inserir o tema MC nas instituições de ensino, pois envolveu a comunidade escolar com atividades de desenhos, leituras e reflexões sobre as problemáticas ambientais para a produção de jornais, com o objetivo de promover a EA nas escolas da RMET. Assim, pode-se pensar na continuidade de projetos dessa natureza que, além de atividades de sensibilização, produzam materiais de divulgação construídos pelos educandos sobre as situações vivenciadas, que trabalhem as questões ambientais.

Dessa maneira, quais as práticas de EA para trabalhar as MC na escola? Os educadores podem pensar em projetos de arborização, consumo sustentável, transportes ecológicos e diminuição da pegada ecológica. Para isso, é possível fazer releituras dos projetos de EA já desenvolvidos pelo NEA/SEMEC, pois os mesmos já contemplam a sensibilização ambiental com foco na problemática dos resíduos sólidos e tráfico de animais silvestres. Por que não pensar em inserir as MC? Emissão de GEE? Perda da biodiversidade? Desmatamento? Queimadas? Problemáticas ambientais contemporâneas e inter-relacionadas com o que já é discutido no contexto escolar e que atendem aos princípios das COM-VIDA na execução de ações previstas na Agenda 21.

Nesse contexto, é importante empregar práticas que possuem abordagem interdisciplinar e transversal, com temáticas que incitem mudanças no comportamento, na responsabilidade socioambiental e na ética ambiental, de forma a estimular outro olhar para a questão climática (JACOBI, 2014). A educação pode contribuir para promover melhor compreensão e capacidade de lidar com as MC e seus efeitos, possibilitar o envolvimento da comunidade, criatividade e conhecimento na busca de soluções e engajamento das partes interessadas no debate e na parceria para responder coletivamente a elas (UNESCO, 2016). Vale ressaltar o pensamento de Paulo Freire:

Não devemos chamar o povo à escola para receber instruções, postulados, receitas, ameaças, repreensões e punições, mas para participar coletivamente da construção de um saber, que vai além do saber de pura experiência feito, que leve em conta as suas necessidades e o torne instrumento de luta, possibilitando-Ihe ser sujeito de sua própria história (FREIRE, 2001, p. 35).

Nessa problematização, Lima e Layrargues (2014) afirmam que o desenvolvimento de propostas pedagógicas é instrumento valioso porque permite: (a) articular a escola e o currículo com os problemas socioambientais; (b) exercitar a pesquisa e a construção coletiva do conhecimento; (c) facultar ao aluno o aprendizado pela experiência; (d) estimular a autonomia e o pensamento crítico; (e) experimentar a transversalidade do saber; (f) abrir à comunidade escolar o contato com a comunidade e com os problemas locais.

Para Monroe et al. (2017), a crescente necessidade da educação eficaz sobre MC e a consciência de que podemos não saber como fazê-la, combinam-se com a criação de oportunidades e a condução de revisão sistemática, com o propósito de elaborar estratégias eficazes na educação sobre MC. Tomando tais medidas, podemos tornar o estudo das MC mais relevante e significativo para os alunos, além de envolver toda a comunidade escolar com atividades e intervenções bem planejadas. 
Por meio da análise dos relatórios do PES, foi possível perceber, portanto, que os projetos de EA não contemplaram o tema MC diretamente, embora Mudanças Climáticas Globais seja um dos tópicos principais da Agenda 21, com a criação da COM-VIDA e a transformação da escola em ambiente sustentável. Isso é preocupante, devido à relevância da temática na formação do cidadão sensibilizado e consciente de suas atitudes com o meio ambiente.

Ademais, foram disponibilizados recursos financeiros do FNDE para tornar a escola um espaço sustentável, com a articulação de questões socioambientais de importância contemporânea. Dessa forma, é preciso refletir sobre o planejamento das ações de EA e a gestão dos recursos financeiros, com diálogo verdadeiro, ou seja, que reconheça as necessidades locais e as problemáticas ambientais, entre a SEMEC e a comunidade escolar, para que os programas de EA promovam conhecimento crítico, transformador e libertador.

\section{Educação, mudanças climáticas e ações antropogênicas}

A educação é a chave para preparar as sociedades para mudanças globais. Desempenha papel crítico para alcançar metas do desenvolvimento sustentável e para colocar em prática o acordo global sobre MC (UNESCO, 2017). Em termos globais, Bai et al. (2018) indicam que 75\% da geração dos GEE, por ações antrópicas, originam-se em atividades majoritariamente urbanas, tais como transporte, construção, indústria e energia. Essa representatividade que as cidades possuem decorre, principalmente, da concentração populacional e do crescimento urbano acelerado.

Nesse contexto, Jacobi (2014) afirma que a multiplicação dos problemas ambientais tem imposto, às diversas disciplinas científicas, temas para os quais não estavam anteriormente preparadas, e cujo enfrentamento demanda alterações nos parâmetros de ensino e pesquisa. Sem renunciar as especialidades disciplinares atualmente em vigor, mas, certamente, contribuindo para sua reformulação e desenvolvimento.

O Currículo do Ensino Fundamental de Teresina contido nas DCT possui unidades temáticas, objetos do conhecimento e habilidades voltadas para as questões ambientais, com destaque para temas, como: biodiversidade, degradação e impactos ambientais, fluxos migratórios, desenvolvimento sustentável e MC. Também aborda as ações antropogênicas e as implicações no meio ambiente, com destaque para a promoção de projetos e atitudes de EA que podem facilitar a educação climática na escola (quadro 4). 
Quadro 4 - Unidades temáticas, objetos do conhecimento e habilidades direcionadas à educação climática no Currículo de Ensino Fundamental de Teresina

\begin{tabular}{|c|c|c|c|}
\hline Unidades Temáticas & $\begin{array}{l}\text { Objetos do } \\
\text { Conhecimento }\end{array}$ & Habilidades & $\begin{array}{l}\text { Componente } \\
\text { Curricular }\end{array}$ \\
\hline \multirow[t]{3}{*}{ Terra e Universo } & Efeito Estufa & $\begin{array}{l}\text { (EF7CI20) Descrever o mecanismo natural do efeito } \\
\text { estufa e seu papel fundamental para o desenvolvimento } \\
\text { da vida na Terra, discutindo as ações humanas } \\
\text { responsáveis pelo seu aumento artificial (queima dos } \\
\text { combustíveis fósseis, desmatamento, queimadas, etc.) } \\
\text { e apontando propostas para a reversão ou controle } \\
\text { desse quadro. }\end{array}$ & \multirow[t]{8}{*}{ Ciências } \\
\hline & $\begin{array}{l}\text { Atmosfera: composição } \\
\text { do ar }\end{array}$ & $\begin{array}{l}\text { EF7CI17) Discutir sobre fenômenos naturais ou } \\
\text { antrópicos que podem alterar a composição do ar. }\end{array}$ & \\
\hline & Clima & $\begin{array}{l}\text { EF8CI06) Discutir iniciativas que contribuam para } \\
\text { restabelecer o equilíbrio ambiental a partir da } \\
\text { identificação de alterações climáticas regionais e } \\
\text { globais provocadas pela intervenção humana. }\end{array}$ & \\
\hline \multirow[t]{4}{*}{ Vida e Evolução } & $\begin{array}{l}\text { Diversidade de ecos- } \\
\text { sistemas: impactos am- } \\
\text { bientais }\end{array}$ & $\begin{array}{l}\text { (EF7CI15) Explicar como os impactos ambientais } \\
\text { provocados por catástrofes naturais ou mudanças } \\
\text { nos componentes físicos, biológicos ou sociais de um } \\
\text { ecossistema afetam suas populações, ameaçando ou } \\
\text { provocando extinção de espécies, alteração de hábitos, } \\
\text { migração, etc. }\end{array}$ & \\
\hline & \multirow[t]{3}{*}{$\begin{array}{l}\text { Ecologia, Biodiversidade } \\
\text { e Preservação }\end{array}$} & $\begin{array}{l}\text { (EF9CI30) Propor iniciativas individuais e coletivas para } \\
\text { a solução de problemas ambientais da cidade ou da } \\
\text { comunidade, com base na análise de ações de consumo } \\
\text { consciente e de sustentabilidade bem-sucedidas }\end{array}$ & \\
\hline & & $\begin{array}{l}\text { EF9CI31) Avaliar as causas e as consequências da ação } \\
\text { humana sobre os ecossistemas. }\end{array}$ & \\
\hline & & $\begin{array}{l}\text { (EF9CI032) Compreender as relações de equilíbrio } \\
\text { dinâmico entre os seres vivos e o meio para a } \\
\text { conservação e preservação da biodiversidade e dos } \\
\text { recursos naturais. }\end{array}$ & \\
\hline Matéria e Energia & Poluição Ambiental & $\begin{array}{l}\text { (EF6Cl22) Propor ações, como campanhas educacionais, } \\
\text { sensibilizando sobre a influência das ações humanas } \\
\text { na degradação ambiental. }\end{array}$ & \\
\hline $\begin{array}{l}\text { Divisão Social e Territo- } \\
\text { rial do Trabalho }\end{array}$ & $\begin{array}{l}\text { Transformações urbano- } \\
\text { industrial na sociedade }\end{array}$ & $\begin{array}{l}\text { (EF09GE21) Compreender os fluxos migratórios } \\
\text { contemporâneos como resultado da profunda } \\
\text { desigualdade socioeconômica construída ao longo } \\
\text { da história (fuga de cérebros, refugiados etc.). }\end{array}$ & Geografia \\
\hline Conexões e Escalas & População brasileira & $\begin{array}{l}\text { (EF07GE18) Compreender as causas dos processos } \\
\text { migratórios no Brasil, refletindo sobre suas } \\
\text { consequências territoriais, sociais, econômicas, } \\
\text { ambientais, etc. }\end{array}$ & \\
\hline $\begin{array}{l}\text { Natureza: meio geográ- } \\
\text { fico e qualidade de vida }\end{array}$ & $\begin{array}{l}\text { Atividades Humanas e } \\
\text { Dinâmica Climática }\end{array}$ & $\begin{array}{l}\text { (EF06GE25) Analisar as implicações para a dinâmica } \\
\text { climática em decorrência das práticas humanas (ilha } \\
\text { de calor, chuva ácida, inversão térmica, etc.). } \\
\text { (EF06GE26) Conhecer as implicações das práticas } \\
\text { humanas na dinâmica climática em Teresina } \\
\text { (inundações, ilhas de calor, etc.). }\end{array}$ & \\
\hline
\end{tabular}

Fonte: adaptado de Teresina (2018).

Nas DCT, observou-se que os alunos do Ensino Fundamental devem compreender o mecanismo natural do efeito estufa, seu papel e as relações com as ações antropogênicas, além de perceber as implicações das práticas humanas para a dinâmica climática, os fluxos migratórios em decorrência das MC, o desenvolvimento sustentável e pensar em atitudes conscientes frente a problemática ambiental.

Para isso, requer aliar o currículo às práticas de EA, que já são propostas para trabalhar os temas socioambientais em Escolas Sustentáveis e a articulação entre gestão, escola e comunidade, uma vez que uma escola - na qual o currículo, a gestão e a estrutura física atuem em conjunto nas questões socioambientais - se torna espaço 
educador sustentável, sendo referência para a comunidade do seu entorno, para seu bairro, cidade, quiçá para a unidade federativa, levando a sustentabilidade do local para o global (SILVA et al., 2019).

Aliás, o desenvolvimento sustentável requer que os indivíduos se considerem cidadãos ambientais e repensem o relacionamento da humanidade e das identidades ambientais, refletindo sobre e como parte que integra o meio natural. Por conseguinte, uma temática que tem suscitado intensos debates para a governança global é a instabilidade climática, assim como as implicações pouco otimistas desse fenômeno para as futuras gerações do Planeta. Dessa maneira, a necessidade de estratégias de mitigação e adaptação são reconhecidas nas políticas e pesquisas em EA e Educação para o Desenvolvimento Sustentável (BLUM et al., 2013; LEVY; ORION; LESHEM, 2018; MENDES, 2020; VERLIE, 2019).

Para tanto, debates em torno da dimensão pedagógica dos conflitos ambientais ensinam que a pesquisa e a educação precisam estar contextualizadas com as realidades locais e globais, para além das ações individuais e comportamentais (COSTA; LOUREIRO; SÁNCHES, 2020). Assim, as atitudes do ser humano em relação à natureza, às crenças ambientais e aos sistemas de valores das pessoas devem ser examinados de maneira eficaz e confiável, de forma que os indivíduos envolvidos em comportamento pró-ambiental entendam o direito de cada espécie, o valor intrínseco da natureza e a obrigação moral dos indivíduos (CAPLOW, 2018; HASAN; KUMAR, 2019; PAÇO; LAVRADOR, 2017).

Diante disso, são importantes as discussões sobre as $M C$ e as ações antropogênicas, uma vez que as atitudes do ser humano interferem no equilíbrio dos ecossistemas, na conservação e na preservação da biodiversidade e dos recursos naturais. Pode-se pensar em iniciativas individuais e coletivas para a solução dos problemas ambientais, com base nas ações de consumo consciente e sustentabilidade. No espaço educativo, os professores podem organizar projetos e campanhas educativas para sensibilizar os educandos sobre a influência humana na degradação ambiental.

Jacobi (2014) afirma que, quanto mais as ações de EA dialogarem com visões pautadas pela existência de riscos promovidos pela sociedade humana - denominados de efeitos antrópicos - maiores serão as possibilidades de formar atores sociais mobilizadores e multiplicadores, tendo em vista que as problemáticas ambientais, suas causas e principais agentes devem ser considerados nos acordos firmados para sua efetividade, adaptação e elaboração de medidas de mitigação.

Para Brennan (2017), o processo educativo não consiste apenas na transferência de conhecimentos e práticas passadas, mas, sobretudo, na formação do indivíduo para a cidadania, dotando-o de capacidade para sobreviver, organizar, pensar, planejar e agir. Há muito o que se debater sobre como equilibrar essas duas dimensões da educação, a tendência dominante das políticas curriculares centradas nos conteúdos e a formação do indivíduo para o exercício da cidadania ambiental, isto é, enfatizar os direitos e deveres com o meio ambiente, considerar a preservação dos recursos naturais e os cuidados com os ecossistemas, com o intuito de minimizar os impactos ambientais.

No contexto de investigação da EA para as MC emerge o questionamento: É possível inserir a educação climática na escola sem a EA? Não existe nenhuma 
resposta pronta, mas a EA oferece aos educadores instrumentos e conhecimentos no desenvolvimento de metodologias para abordar as MC na escola, de forma a promover a educação climática, com estratégias de adaptação e mitigação, além de contribuir para a construção de valores ambientais e sociais que favoreçam a mudança de atitude e ações mais conscientes diante da crise ambiental contemporânea.

Após análise do Currículo do Ensino Fundamental de Teresina, na perspectiva da educação climática, a discussão sobre as MC ainda é superficial. No tópico que trata do Efeito Estufa, poderiam ser feitas abordagens aliando as questões já trabalhadas para contemplar o tema Mudanças Climáticas Globais que, além de tratar do efeito estufa e do seu papel no Planeta, dá espaço para reflexões sobre o desenvolvimento sustentável, perda da biodiversidade, refugiados ambientais, dinâmica climática e ações antropogênicas. Ainda podem ser utilizadas práticas de EA para articular as MC na escola, que são indispensáveis, em especial, quando se trata de Escolas Sustentáveis.

\section{Considerações finais}

Após análise dos resultados, concluiu-se que, para ampliação das discussões sobre as MC no contexto das Escolas Sustentáveis, primeiramente, é importante refletir como essa questão está inserida na escola; segundo, como os educadores trabalham essa temática dentro do currículo, e, por fim, como abordar esse tema nos projetos de EA desenvolvidos pelas COM-VIDA. Dessa forma, buscar medidas de adaptação e mitigação das $M C$, com diretrizes ou procedimentos de participação ampla das escolas, governos, empresas e cidadãos comuns, cada um cumprindo a sua parte, demonstrando responsabilidade social e sustentabilidade.

A RMET possui compromisso com a questão ambiental, promovendo projetos, ações e atividades de EA, que envolvem a escola e a comunidade, além de incentivar a capacitação docente na área e realizar o acompanhamento das instituições por meio do NEA. Todavia, no contexto das MC, as discussões ainda são sucintas, ou seja, nas propostas pedagógicas desenvolvidas pelo PES, prevaleceram temas como resíduos sólidos, violência e tráfico de animais silvestres, mesmo que a MC seja um tema socioambiental e contemporâneo, de abrangência local e global, contemplado pela COM-VIDA.

O Currículo do Ensino Fundamental do município de Teresina traz conteúdos, habilidades relacionadas às $M C$, com incentivos à promoção de atividades de sensibilização e conscientização dos indivíduos diante das questões ambientais. Entretanto, é preciso pensar em práticas de EA para trabalhar as MC dentro da escola, a fim de promover a educação climática, com medidas consistentes de EA para a formação do cidadão consciente e sensibilizado com a problemática do clima.

Faltam estratégias direcionadas especificamente para integrar a educação climática à EA, isso pode ser iniciado com o projeto Eco Kids/Eco Teens pelo potencial que possui para abordar as MC em escolas sustentáveis, por contribuir com a sensibilização ambiental, inter-relação entre escola e comunidade e participação ativa dos educandos nas atividades, visto que os materiais de divulgação são produzidos pelos próprios alunos.

Além disso, os educadores e os gestores podem fazer uma releitura dos projetos desenvolvidos pelo NEA/SEMEC, de forma a inter-relacionar com as Mudanças Climáticas Globais e particularidades locais, desenvolvendo atividades de EA que 
abordem a temática na escola, uma vez que as ações antropogênicas sejam apontadas como energia de ativação das MC. A EA, por sua vez, tem papel fundamental na transformação social, na valorização do coletivo, tornando o ambiente dinâmico, participativo, contribuindo na construção de valores sociais e ambientais.

\section{Agradecimentos}

Os autores agradecem ao Núcleo de Educação Ambiental (NEA), à Secretaria Municipal de Educação de Teresina (SEMEC) e à Coordenação de Aperfeiçoamento de Pessoal de Nível Superior (CAPES).

\section{Referências}

ABREU, G. S.; ANDRADE, C. S. P. Geotecnologias aplicadas à caracterização da temperatura da superfície na cidade de Teresina (PI). Acta Geográfica, Boa Vista, v. 13, n. 32, p. 28-47, 2019.

ANDRADE, C. S. P. Teresina e clima: indissociabilidades no estudo da cidade. Revista Equador, Teresina, PI, v. 5, n. 3, p. 398-420, 2016. Disponível em: https://revistas.ufpi.br/index.php/ equador/article/view/5056. Acesso em: 7 out. 2021.

BAI, X. et al. Six research priorities for cities and climate change. Nature, London, v. 555, n. 7694, p. 23-25, 2018. DOI: https://doi.org/ghxwd4.

BARDIN, L. Análise de conteúdo. Lisboa: Edições 70, 2011.

BELASCO, G. C.; DAMIANO, M.; BARRETO, Y. S.; MUNDO, J. A. L.; BONZANINI, T. K. Comissão de meio ambiente e qualidade de vida na escola (com-vida): uma investigação em documentos oficiais. Holos Environment, Rio Claro, SP, v. 20, n. 1, p. 60-72, 2020. DOI: https://doi.org/gznt.

BLUM, N.; NAZIR, J.; BREITING, S.; GOH, K. C.; PEDRETTI, E. Balancing the tensions and meeting the conceptual challenges of education for sustainable development and climate change. Environmental Education Research, Abingdon, v. 19, n. 2, p. 206-217, 2013. DOI: https://doi.org/ gmgzmt.

BLUMENTHAL, I.; KROPP, J. P. Climate change: changes begin in the mind and need accompaniment. Geographische Rundschau, Germany, v. 71, n. 12, p. 6-11, 2019.

BRASIL. Ministério do Meio Ambiente. Formando com-vida: construindo Agenda 21 na escola. 2. ed. rev. ampl. Brasília: MMA, 2007. Disponível em: http://portal.mec.gov.br/dmdocuments/ publicacao7.pdf. Acesso em: 6 out. 2021.

BRENNAN, M. Struggles for teacher education in the age of the anthropoceno. Journal of Education, Durban, n. 69, p. 43-66, 2017.

BUENO, S. Minidicionário da lingua portuguesa. 2. ed. São Paulo: FTD, 2007.

BUSCH, K. C.; HENDERSON, J. A.; STEVENSON, K. T. Expanding epistemologies and methodologies in research on climate change education. Environmental Education Research, Abingdon, v. 25, n. 6, p. 955-971, 2019.

CAPLOW, S. The presentation of environmental values, beliefs, and norms in live animal interpretive experiences. Environmental Education Research, Abingdon, v. 25, n. 8, p. 1158-1173, 2018. DOI: https://doi.org/gznx.

COSTA, R. N.; LOUREIRO, R.; SÁNCHEZ P., C. Aprender com a natureza e a dimensão pedagógica dos conflitos ambientais: abordagem da ecologia política nas discussões do clima. APEduC Revista, Vila Real, Portugal, v. 1, n. 1, p.188-190, 2020. Disponível em: https://apeducrevista.utad. pt/index.php/apeduc/article/view/84. Acesso em: 7 out. 2021. 
ELALI, G. A. O ambiente da escola - o ambiente na escola: uma discussão sobre a relação escolanatureza em educação infantil. Estudos de Psicologia, Natal, v. 8, n. 2, p. 309-319, 2003. DOI: https://doi.org/cz32k3.

FAVERO, R. Protagonismo da criança na apropriação do espaço escolar da educação infantil. 2017. Trabalho de Conclusão de Curso (Licenciatura em Pedagogia) - Universidade Federal da Fronteira Sul, Erechim, 2017. Disponível em: https://rd.uffs.edu.br/handle/prefix/1805. Acesso em: 7 out. 2021.

FREIRE, P. Educação como prática de liberdade. 30. ed. Rio de Janeiro: Paz e Terra, 2007.

FREIRE, P. A educação na cidade. São Paulo: Cortez, 1991.

FREIRE, P. Política e educação. 5. ed. São Paulo: Cortez, 2001.

GIL, A. C. Como elaborar projetos de pesquisa. 4. ed. São Paulo: Atlas, 2008.

HASAN, M. K.; KUMAR, L. Comparison between meteorological data and farmer perceptions of climate change and vulnerability in relation to adaptation. Journal of Environmental Management, Amsterdam, v. 237, p. 54-62, 2019. DOI: https://doi.org/gf2f9r.

HESS, D. J.; MAKI, A. Climate change belief, sustainability education, and political values: Assessing the need for higher-education curriculum reform. Journal of Cleaner Production, Amsterdam, v. 228, p. 1157-1166, 2019. DOI: https://doi.org/gzq3.

JACOBI, P. R. Mudanças climáticas e ensino superior: a combinação entre pesquisa e educação. Educar em Revista, Curitiba, n. esp. 3, p. 57-72, 2014. DOI: https://doi.org/gzq4.

KRASNY, M. E.; DUBOIS, B. Climate adaptation education: embracing reality or abandoning environmental values. Environmental Education Research, Abingdon, v. 25, n. 6, p. 883-894, 2016. DOI: https://doi.org/ggkvg6.

KUSTER, E. L.; FOX, G. A. Current state of climate education in natural and social sciences in the USA. Climatic Change, Dordrecht, v. 141, n. 4, p. 613-626, 2017. DOI: https://doi.org/gzq5.

LEVY, A.; ORION, N.; LESHEM, Y. Variables that influence the environmental behavior of adults. Environmental Education Research, Abingdon , v. 24, n. 3, p. 307-325, 2018. DOI: https://doi.org/ gzq6.

LIMA, G. F. C.; LAYRARGUES, P. P. Mudanças climáticas, educação e meio ambiente: para além do conservadorismo dinâmico. Educar em Revista, Curitiba, n. esp. 3, p. 73-88, 2014. DOI: https://doi. org/gzq7.

MENDES, M. V. I. Mudança global do clima as cidades no Antropoceno: escalas, redes e tecnologias. Caderno Metrópole, São PAulo, v. 22, n. 48, p. 343-363, 2020. DOI: https://doi.org/ gzq8.

MESQUITA, P. S.; BRAZ, V. S.; MORIMURA, M. M.; BURSZTYN, M. Percepções de universitários sobre as mudanças climáticas e seus impactos: estudo de caso no Distrito Federal. Ciência \& Educação, Bauru, v. 25, n. 1, p. 181-198, 2019. DOI: https://doi.org/gzq9.

MONROE, M.; PLATE, R.; OXARART, A.; BOWERS, A.; CHAVES, W. Identifying effective climate change education strategies: a systematic review of the research. Environmental Education Research, Abingdon, v. 25, n. 6, p. 791-812, 2017. DOI: https://doi.org/ghtfbb.

NÓBREGA, M. L. S.; CLEOPHAS, M. G. A educação ambiental como proposta de formação de professores reflexivos: das práticas contextualizadas à ambientalização no ensino de ciências. Inter-Ação, Goiânia, v. 41, n. 3, p. 605-628, 2016. DOI: https://doi.org/10.5216/ia.v41i3.41884.

OJALA, M. Emotions, values and education for a sustainable future: promoting critical emotional awareness in climate education. Acta Didactica Norge, Oslo, v. 13, n. 2, p. 1-17, 2019. 
PAÇO, A.; LAVRADOR, T. Environmental knowledge and attitudes and behaviours towards energy consumption. Journal of Environmental Management, Amsterdam, v. 197, p. 384-392, 2017. DOI: https://doi.org/gbhwkm.

SANTOS, P. F.; DIAS, A. M.; COSENZA, A.; FONSECA, J. A.; SILVA, M. A. Impactos e injustiças ambientais: significações de atores que constituem um conflito socioambiental. Pesquisa em Educação Ambiental, Rio Claro, SP, v. 12, n. 1, p. 100-114, 2017. DOI: https://doi.org/gzsf.

SATO, M. Educação ambiental. São Carlos: Rima, 2003.

SATO, M. Mitopoética das águas salgadas: relatório parcial de pós-doutorado. Cuiabá: GPEA: UFMT, 2014. (mimeo).

SATO, M. (coord.). Os condenados da pandemia. Cuiabá: GPEA: Ed. UFMT, 2020.

SILVA, A. O. S.; SILVA, S. L. C.; SILVA, D. C.; BARZANO, M. A. L.; SANTOS, S. O. Programa dinheiro direto na escola: escolas sustentáveis, em um município do estado da Bahia: contribuições, desafios e perspectivas. Desenvolvimento e Meio Ambiente, Curitiba, v. 52, p. 302-324, 2019. DOI: https://doi.org/gzrb.

SILVA, M. L.; BASTOS, R. Z.; RIBEIRO, M. G. C. Reflexões sobre o programa escolas sustentáveis na política pública de educação ambiental de Ananindeua. Remoa: Revista Monografias Ambientais, Santa Maria, RS, v. 18, n. 11, p. 1-9, 2019. DOI: https://doi.org/gzrc.

SILVA, V. P.; FRANÇA, G. L. S. Percepções de mudanças do clima, impactos e adaptação para sertanejos do semiárido. Revista Brasileira de Climatologia, Curitiba, v. 14, v. 22, p. 229-248, 2018. DOI: https://doi.org/gzrf.

SOUZA, C.; SATO, M. Justiça climática e educação ambiental. In: PEREIRA, V.; MADEIRA, M.; SOUZA, E.; STEUCK, E. (org.). Educação ambiental em tempos de crise: por uma ontologia dae. Juiz de Fora: Garcia Ed., 2019. p. 59-74.

TEIXEIRA, R. L. P.; PESSOA, Z. S. Mudanças climáticas, experimentação de políticas públicas e capacidade adaptativa na cidade de Curitiba/PR-Brasil. Inter-Legere, Natal, RN, v. 3, n. 27, p. 1-28, 2020. Disponível em: https://periodicos.ufrn.br/interlegere/article/view/18712. Acesso em: 8 out. 2021.

TEIXEIRA, R. L. P.; PESSOA, Z. S.; DI GIULIO, G. M. Mudanças climáticas e capacidade adaptativa no contexto da cidade do Natal/RN, Brasil. Geotemas, Pau dos Ferros, RN, v. 10, n. 1, p. 95-115, 2020. Disponível em: http://natal.uern.br/periodicos/index.php/GEOTemas/article/view/1824. Acesso em: 8 out. 2021.

TERESINA. Prefeitura Municipal. Diretrizes curriculares. Teresina: Secretaria Municipal de Educação e Cultura, 2008.

TERESINA. Prefeitura Municipal. Diretrizes curriculares. Teresina: Secretaria Municipal de Educação e Cultura, 2018.

UNESCO. Action for climate empowerment: guidelines for accelerating solutions through education, training and public awareness. Paris: Unesco, 2016. Disponível em: https://cutt. ly/4EMmsRr. Acesso em: 7 out. 2021.

UNESCO. Changing minds, not the climate: the role of education. Paris: UNESCO, 2017. Disponível em: https://cutt.ly/vEMmZpk. Acesso: 20 abr. 2020.

VALOIS, R. S.; CAVALARI, R. M. F. COM-VIDA: dos documentos à sua implementação em duas escolas de Teresina, Piauí. REMEA, Rio Grande, RS, p. 84-104, 2015. (Número especial).

VERLIE, B. Bearing worlds: learning to live-with climate change. Environmental Education Research, Abingdon, v. 25, n. 5, p. 751-766, 2019. DOI: https://doi.org/gf633b. 